\title{
Optical and Dielectric Properties of Eu- and Y-Polytantalate Thin Films
}

Vladimir Vasilyev*, Alvin Drehman, Helen Dauplaise, Lionel Bouthillette, Air Force Research Laboratory, Sensors Directorate, Hanscom AFB, MA Mark Roland, Solid State Scientific Corp., Hollis, NH Alex Volinsky, University of South Florida, Department of Mechanical Engineering, Tampa, FL Stefan Zollner, Wentao Qin Motorola, Inc. Advanced Products R\&D Laboratory MD EL622, Tempe, AZ

\begin{abstract}
Due to their highly efficient photo-luminescent (PL) characteristics, the physical properties of rare-earth polytantalates, $\mathrm{RETa}_{7} \mathrm{O}_{19}(\mathrm{RE}=\mathrm{Eu}$ and $\mathrm{Y})$ were further studied. AFM, SEM, HRTEM, $\mathrm{x}$-ray reflectometry, spectroscopic ellipsometry and standard dielectric testing were used to determine film thickness, roughness, index of refraction, band-gap, dielectric constant, leakage current and breakdown field for as-deposited (amorphous) and post-annealed (crystalline) films. Structural and morphological properties of the Film/ $/ \mathrm{SiO}_{2} / \mathrm{Si}$ interfaces were also examined.
\end{abstract}

\section{INTRODUCTION}

Previously [1] we reported that oriented polycrystalline thin films of stoichiometric Eu- and Y-polytantalates $\left(\mathrm{Eu}_{\mathrm{x}} \mathrm{Y}_{1-\mathrm{x}} \mathrm{Ta}_{7} \mathrm{O}_{19}, \mathrm{x}=0-1.0\right)$ can be grown by $\mathrm{RF}$ sputtering on $\mathrm{Si}$, fused silica, and sapphire substrates. These films exhibited an intense red PL under UV excitation.

Similar to $\mathrm{Ta}_{2} \mathrm{O}_{5}$ and rare-earth oxides, which are currently being considered as an alternative to silicon dioxide as high- $\mathrm{K}$ dielectrics for devices below $0.1 \mu \mathrm{m}$ [2-5], these rare-earth tantalate films may be of interest as new materials possessing a high dielectric constant. While basic physical properties of these compounds have yet to be rigorously studied, this paper reports results used to determine the refractive index, band-gap, dielectric constant, leakage current, and breakdown field for these as-deposited amorphous and post-annealed crystalline films.

\section{EXPERIMENTAL}

Films of Eu- and Y-polytantalates were deposited by RF diode sputtering in 6 mTorr Ar as described in [1]. For source material, sintered targets were made of stoichiometric mixes of pure grade oxides $\left(\mathrm{Eu}_{\mathrm{x}} \mathrm{Y}_{1-\mathrm{x}} \mathrm{Ta}_{7} \mathrm{O}_{19}, \mathrm{x}=1,0.5\right.$, and 0$)$. The first group of films (30 to $100 \mathrm{~nm}$ thick) was deposited onto Si (100) wafers and used for SEM, HRTEM, spectroscopic ellipsometry, and $\mathrm{x}$-ray reflectometry measurements. A second group of films $(\sim 500 \mathrm{~nm})$, used for dielectric determination, was deposited onto $\mathrm{Ti}(20 \mathrm{~nm}) / \mathrm{Pt}(150 \mathrm{~nm})$ coated $\mathrm{Si}(100)$ wafers. These films were characterized before and after annealing in oxygen at 900 to $1000^{\circ} \mathrm{C}$ for 0.5 to $1 \mathrm{hrs}$.

$\mathrm{X}$-ray reflectometry measurements: $\mathrm{X}$-Ray reflectometry (XRR) is a useful technique for measuring thin film thickness up to $2000 \AA$. By fitting x-ray intensity versus beam incident angle $[6,7]$ the film thickness, density, and layer roughness can be determined. Film thickness is the easiest and most accurate parameter to fit, and is determined by the fringe periodicity. The other parameters depend on absolute intensity levels, which can be affected by experimental 
variables. Eu- and Y-polytantalate films were measured with a high-resolution diffractometer, using $\mathrm{CuK} \alpha_{1}$ radiation. A $100 \mu \mathrm{m}$ slit was placed at the x-ray source and two $200 \mu \mathrm{m}$ slits were placed in front of the detector. The data was fitted assuming a single film layer on top of $\mathrm{SiO}_{2} / \mathrm{Si}$. The software described in [8] was used to calculate film thickness, density, and layer roughness. The GOF (Goodness Of Fit) was calculated using the least-squares method. Lower numbers correspond to a better fit, with a 0.05 GOF considered to be a "good" fit. Atomic force microscopy (AFM) was also used to measure film roughness.

SEM, HRTEM Images: SEM images of deposited and annealed films were obtained with a backscatter detector. SEM images of the as deposited amorphous films had a low contrast, therefore these films were further examined using high resolution TEM (HRTEM).

Optical Measurements: Index of refraction and band gap were measured using a variable-angle rotating-analyzer spectroscopic ellipsometer without a compensator. The data was fitted using a Tauc-Lorentz oscillator model, assuming an ideal approach (parallel interfaces, single layer, no thickness variations, no roughness), which usually gives a good fit for most amorphous materials $[7,9]$. A thin film spectrometer was also used to measure film thickness.

Dielectric constant determination: Metal contacts $(500 \AA \mathrm{Ti} / 2000 \AA \mathrm{Au})$ with an overall area ranging between $1 \times 10^{-3} \mathrm{~cm}^{2}$ to $5 \times 10^{-3} \mathrm{~cm}^{2}$ were deposited onto the films using electron beam evaporation. A 2D surface profiler was used to determine the contact dimensions. The dielectric constant, $\mathrm{K}$, was calculated using results obtained from capacitance-voltage $(\mathrm{C}-\mathrm{V})$ measurements (LCR Meter, at $1 \mathrm{MHz}$ ), the area of the metal contacts over the film, and film thickness values as determined by optical spectroscopy. A DC source was used to measure leakage current and breakdown voltage. The breakdown field was defined as an average applied field to the various contact areas when the current density through the dielectric exceeded $4 \times 10^{-4} \mathrm{~A} / \mathrm{cm}^{2}$ as described in [5] for $\mathrm{Ta}_{2} \mathrm{O}_{5}$ films.

\section{RESULTS AND DISCUSSION}

Table I shows data, obtained from XRR measurements. While the GOF values are quite good for amorphous films, higher GOF values are obtained for crystalline films, which are rougher

Table I. XRR measurements data for Y- and Eu-polytantalate films.

\begin{tabular}{|c|c|c|c|c|c|c|c|c|}
\hline Films & $\begin{array}{c}\text { Thickness, } \\
\text { \& }\end{array}$ & $\begin{array}{c}\text { Roughness, } \\
\text { A }\end{array}$ & $\begin{array}{c}\text { Roughness, } \\
A, \\
\text { AFM data }\end{array}$ & $\begin{array}{c}\text { Density, } \\
g / \mathrm{cm}^{3}\end{array}$ & $\begin{array}{c}\text { Calculated } \\
\text { Density, } \\
\mathrm{g} / \mathrm{cm}^{3}\end{array}$ & $\begin{array}{c}\mathrm{SiO}_{2} \\
\text { Thickness, } \\
\AA\end{array}$ & $\begin{array}{c}\mathrm{SiO}_{2} \\
\text { Roughness, } \\
\frac{8}{\mathrm{~A}}\end{array}$ & $\mathrm{GOF}$ \\
\hline $\mathrm{YTa}_{7} \mathrm{O}_{19}$ amorphous & 811 & 6 & 4.4 & 7.14 & & 52 & 13 & 0.026 \\
\hline $\mathrm{YTa}_{7} \mathrm{O}_{19}$ annealed & 728 & 13 & 12 & 8.68 & 8.32 & 50 & 19 & 0.07 \\
\hline $\mathrm{EuTa}_{7} \mathrm{O}_{19}$ amorphous & 918 & 5 & 2.2 & 6.69 & & 70 & 23 & 0.05 \\
\hline EuTa $\mathrm{O}_{19}$ annealed & 910 & 28 & 26 & 8.01 & 8.57 & 67 & 8 & 0.087 \\
\hline $\mathrm{Y}_{0.5} \mathrm{Eu}_{0.5} \mathrm{~T}_{7} \mathrm{O}_{19}$ amorph. & 1049 & 7 & 5.9 & 6.47 & & 72 & 25 & 0.079 \\
\hline $\mathrm{Y}_{0.5} \mathrm{Eu}_{0.5} \mathrm{Ta}_{7} \mathrm{O}_{19}$ anneal. & 1042 & 28 & 32 & 7.9 & 8.48 & 73 & 12 & 0.086 \\
\hline $\mathrm{Y}_{0.5} \mathrm{Eu}_{0.5} \mathrm{Ta}_{7} \mathrm{O}_{19}$ amorph. & 380 & 5 & 2.5 & 7.7 & & 61 & 14 & 0.039 \\
\hline $\mathrm{Y}_{0.5} \mathrm{Eu}_{0.5} \mathrm{Ta}_{7} \mathrm{O}_{19}$ anneal. & 314 & 13 & 17 & 7.56 & 8.48 & 82 & 25 & 0.105 \\
\hline
\end{tabular}


and had rougher film/ $/ \mathrm{SiO}_{2}$ interface. The data from Table I also correlate quite well with AFM film surface roughness measurements obtained in [1] and density values for sintered polytantalates [10]. Formation of stoichiometric compounds was confirmed by PL spectra (not shown) as in [1].

Fig.1, $a, b$, shows the crystalline structure of the annealed polytantalate films. These films are composed of elongated faceted blocks that are preferentially oriented with the $[00 l]$-axis along the substrate surface. An interfacial layer exists (Fig.1, c) between the film and the Si, which is believed to be primarily $\mathrm{SiO}_{2}$.

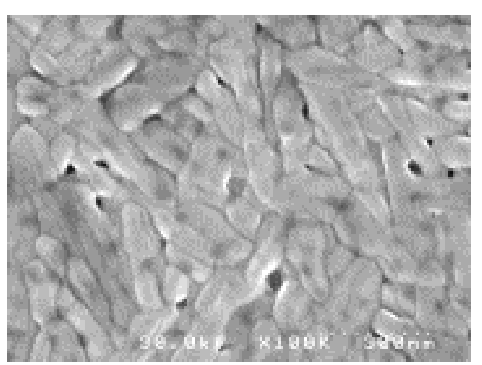

$a$

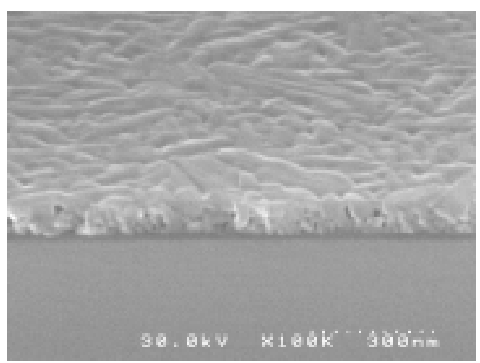

$b$

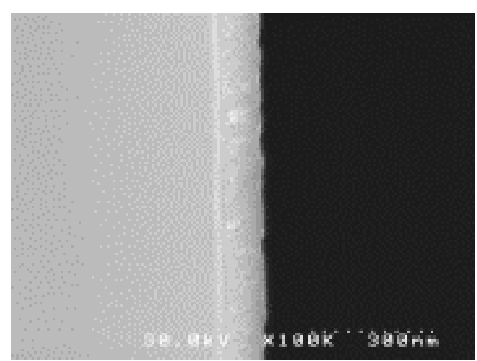

c

Figure 1. SEM images of EuTa $\mathrm{O}_{19}$ films crystallized after annealing in air at $900{ }^{\circ} \mathrm{C}$.

$\mathrm{RETa}_{7} \mathrm{O}_{19}(\mathrm{RE}=\mathrm{La}, \mathrm{Ce}, \mathrm{Pr}, \mathrm{Eu}, \mathrm{Nd}, \mathrm{Dy})$ belongs to the hexagonal symmetry group P-6c2 [1116]. The morphology of $\mathrm{EuTa}_{7} \mathrm{O}_{19}$ single crystals is characterized by the presence of two hexagonal prisms ([h00] and [hh0] - facets), a pinacoid, and two hexagonal pyramids. This can be seen in Fig.2a, with comparison to x-ray data $[10,15]$. These SEM images confirmed our previous X-ray data [1] that Eu- and Y-polytantalate films crystallize with [110] preferential vertical orientation. This orientation is also inherent in the films that were deposited onto a metallized $(\mathrm{Pt})$ surface.
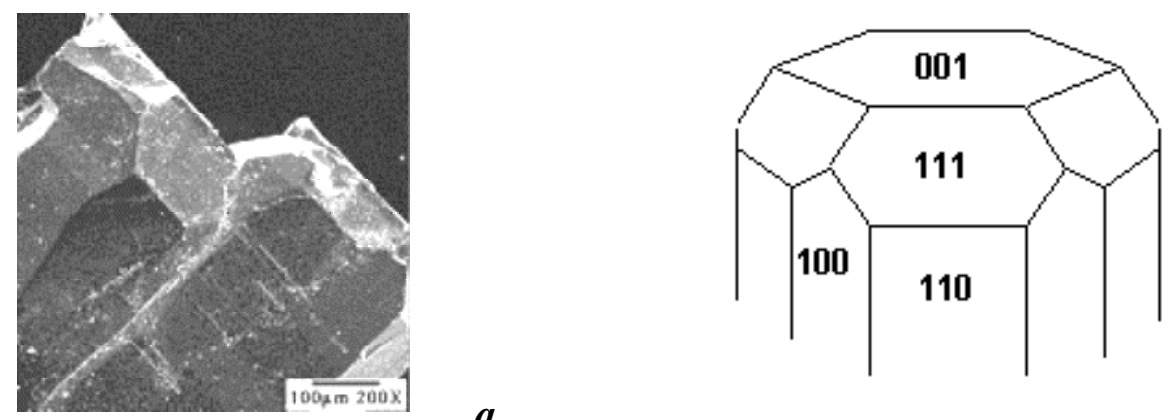

\section{$a$}

Figure 2. (a) $\mathrm{EuTa}_{7} \mathrm{O}_{19}$ single crystals image and $(b)$ their basic morphology picture.

Bright-field HRTEM images of as-deposited films show no diffraction contrast (Fig. $3 b$ ). This is consistent with the electron diffraction pattern from the film (Fig. 3a), indicating that the films are amorphous. A second amorphous layer exists between the film and the Si substrate, which is likely to be $\mathrm{SiO}_{2}$, and has a relatively smooth interface with the film (Fig. 3, c, d). Thicknesses from the HRTEM images are consistent with the XRR measurements (Table I).

Table II and Figure 4 present values of thickness and optical constants for $\mathrm{YTa}_{7} \mathrm{O}_{19}$ and 

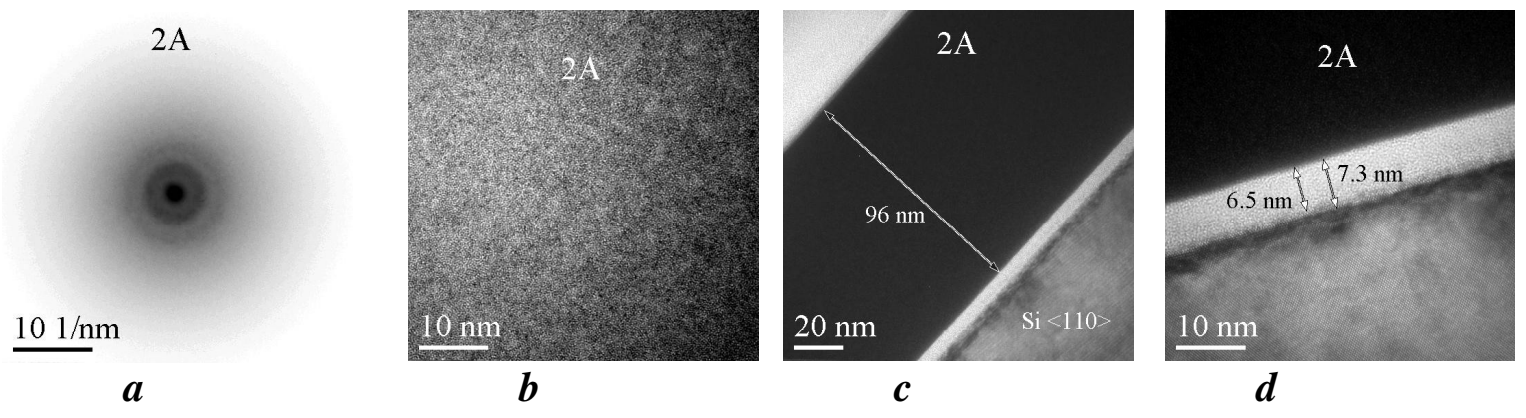

Figure 3. a) The electron diffraction pattern, c), d) high resolution TEM images of $\mathrm{EuTa}_{7} \mathrm{O}_{19} / \mathrm{SiO}_{2} / \mathrm{Si}$-interfaces, and (b) from the center of $\mathrm{EuTa}_{7} \mathrm{O}_{19}$ film.

$\mathrm{EuTa}_{7} \mathrm{O}_{19}$ films as obtained by spectroscopy and spectroscopic ellipsometry for the same samples used for the XRR measurements. In Fig.4, the index of refraction, $n$, and extinction coefficient, $k$, are plotted versus photon energy over the 0.7 to $5.6 \mathrm{eV}$ range. For an optically absorbing medium, the complex index of refraction $\boldsymbol{n}$ consists of the real part, $n$, and the imaginary part, $k$, or the extinction coefficient, which is related to absorption coefficient, $\alpha$, by:

$$
k=\alpha \lambda_{0} / 4 \pi
$$

where $\lambda_{0}$ is the wavelength in vacuum. Tauc [17] proposed an equation that denotes the relation between energy and absorption:

$$
\alpha(E)=\left(E-E_{g}\right)^{1 / 2} / E
$$

where $E$ is the photon energy and $E_{g}$ is the optical band gap. The "Tauc-gap" is often used to estimate the real material energy gap and is obtained by extrapolation of the plotted dependence (2) as a straight line towards an intersection with the E axis $(\alpha(E)=0)$, giving the optical band gap value.

Table II. Spectroscopy (thicknesses) and spectroscopic ellipsometry (n, band gap) data for Y- and Eu- polytantalate films.

\begin{tabular}{|l|c|c|c|c|}
\hline \multicolumn{1}{|c|}{ Film } & $\begin{array}{c}\mathrm{Film} \\
\text { Thickness, } \AA\end{array}$ & $\begin{array}{c}\mathrm{SiO}_{2} \\
\text { Thickness, } \AA\end{array}$ & $\begin{array}{c}\mathrm{n}, \\
400-650 \mathrm{~nm}\end{array}$ & Band gap, eV \\
\hline $\mathrm{YTa}_{7} \mathrm{O}_{19}$ amorphous & 770 & 80 & $2.17-2.02$ & 4.6 \\
\hline $\mathrm{YTa}_{7} \mathrm{O}_{19}$ annealed & 830 & 235 & $2.10-1.99$ & 4.9 \\
\hline EuTa $_{7} \mathrm{O}_{19}$ amorphous & 925 & 65 & $2.21-2.03$ & 4.6 \\
\hline EuTa $_{7} \mathrm{O}_{19}$ annealed & 950 & 305 & $2.17-2.06$ & 5 \\
\hline $\mathrm{Y}_{0.5} \mathrm{Eu}_{0.5} \mathrm{~T}_{7} \mathrm{O}_{19}$ amorph. & 1140 & 90 & $2.22-2.06$ & 4.6 \\
\hline $\mathrm{Y}_{0.5} \mathrm{Eu}_{0.5} \mathrm{Ta}_{7} \mathrm{O}_{19}$ annealed & 1150 & 240 & $2.14-2.03$ & 4.4 \\
\hline
\end{tabular}

Figure 4 shows that the wavelength dependent values of both $n$ and $k$ are very similar in the $\mathrm{YTa}_{7} \mathrm{O}_{19}$ and $\mathrm{EuTa}_{7} \mathrm{O}_{19}$ films. The band gap for the amorphous films was calculated from the slope of the absorption edge, and is comparable with $\mathrm{Ta}_{2} \mathrm{O}_{5}(\sim 4.5 \mathrm{eV})$ data [2 ]. The annealed crystalline films have a slightly higher Tauc-gap value despite the somewhat lower onsets of 
absorption. The absorption peaks of the crystalline films are a little sharper and taller, and may be due to the greater crystallinity and roughness of the annealed films. The fit for these films above $5.5 \mathrm{eV}$ becomes less reliable due to increased roughness and possible thickness variations and a breakdown of the assumption of plan-parallel interfaces.

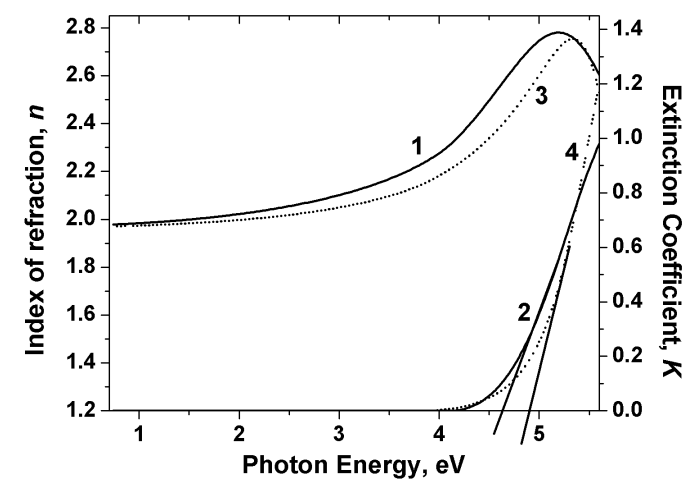

Figure 4. Indexes of refraction, $n$, and extinction coefficients, $k$, for $\mathrm{YTa}_{7} \mathrm{O}_{19}$ films, as deposited (1-n, 2-k), and after annealing $(3-n, 4-k)$. The extrapolation of absorption lines $(2,4)$ using slops to the Energy-axis gives the "Tauc-gap", which is associated with the real energy gap in the films.

Table III shows the results of electrical testing. The dielectric constant, $\mathrm{K}$, obtained for amorphous films is comparable to the values of amorphous $\mathrm{Ta}_{2} \mathrm{O}_{5}(\sim 23)$ [5]. The measured $\mathrm{K}$ value for annealed films is significantly lower, possibly due to the non-uniformity and anisotropy, and porosity of crystalline material (Fig.1). The density, obtained by XRR (Table I), also points to a somewhat porous character of annealed films. The annealing temperature of 900 ${ }^{\circ} \mathrm{C}$ for $1 \mathrm{~h}$ was dictated by the necessity to synthesize a completely stoichiometric composition, which is very important for obtaining good luminescent films. Uniform and fully dense films are required for dielectric applications, and such films would most likely have a very fine grain

Table III. $C-V, I-V$ and breakdown field measurements results for Y-Eu-polytantalate films.

\begin{tabular}{|l|c|c|c|c|}
\hline \multicolumn{1}{|c|}{ Films } & Thickness, & $\begin{array}{c}\text { Dielectric } \\
\text { constant, } \\
\mathrm{Km}\end{array}$ & $\begin{array}{c}\text { Leakage Current } \\
\text { Density at } \\
1 \mathrm{MV} / \mathrm{cm}, \mathrm{A} / \mathrm{cm}^{2}\end{array}$ & $\begin{array}{c}\text { Breakdown Field } \\
\text { at the LCD }>4 \times 10^{-4} \\
\mathrm{~A} / \mathrm{cm}^{2}, \mathrm{MV} / \mathrm{cm}\end{array}$ \\
\hline $\mathrm{YTa}_{7} \mathrm{O}_{19}$ amorphous & 425 & 22.8 & $3.6 \times 10^{-8}$ & \\
\hline $\mathrm{YTa}_{7} \mathrm{O}_{19}$ crystall. & 440 & 8.6 & $2.9 \times 10^{-7}$ & 3.3 \\
\hline $\mathrm{EuTa}_{7} \mathrm{O}_{19}$ amorph. & 510 & 23.7 & $2.6 \times 10^{-8}$ & \\
\hline $\mathrm{EuTa}_{7} \mathrm{O}_{19}$ crystall. & 520 & 6.6 & $6.7 \times 10^{-7}$ & 3.45 \\
\hline $\mathrm{Y}_{0.5} \mathrm{Eu}_{0.5} \mathrm{Ta}_{7} \mathrm{O}_{19}$ am. & 770 & 25.3 & $1.2 \times 10^{-8}$ & \\
\hline $\mathrm{Y}_{0.5} \mathrm{Eu}_{0.5} \mathrm{Ta}_{7} \mathrm{O}_{19}$ cryst. & 780 & 12.9 & $1.4 \times 10^{-8}$ & $>3.5$ \\
\hline
\end{tabular}

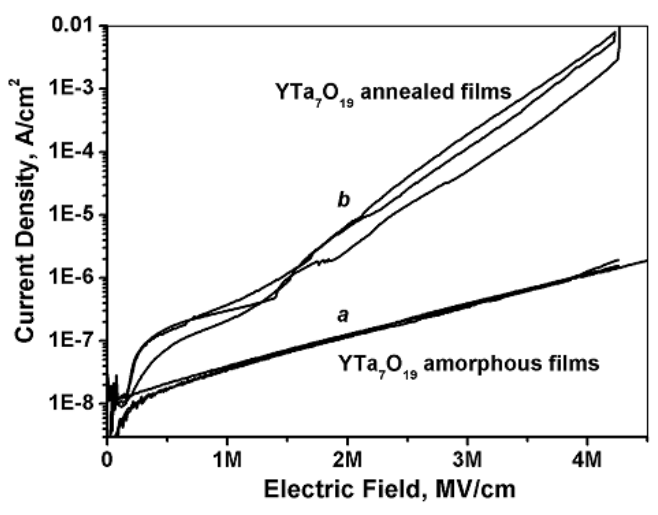

Figure 5. Current density vs. electric field for $\mathrm{YTa}_{7} \mathrm{O}_{19}$ films (a) as-deposited and (b) annealed at $900{ }^{\circ} \mathrm{C}$ in air. Note that consistent data is obtained for all three electrodes areas for the asdeposited films. In contrast, we obtained significant scatter in the data for the annealed films depending on the electrode size. We attribute this to some non-uniformity as a result of high temperature annealing. 
structure and would require lower annealing temperatures to form, which could result in films with some second phase precipitates present. Although the leakage current does increase after high temperature annealing, it should be noted that at an applied electric field of $\sim 1 \mathrm{MV} / \mathrm{cm}$ the leakage current is only in the range of $6 \times 10^{-7}$ to $1.4 \times 10^{-8} \mathrm{~A} / \mathrm{cm}^{2}$, which is adequate for application in 64 and $256 \mathrm{Mbit}$ DRAM. EuTa $\mathrm{O}_{19}$ and $\mathrm{Eu}_{0.5} \mathrm{Y}_{0.5} \mathrm{Ta}_{7} \mathrm{O}_{19}$ (not shown) have I-V curves similar to $\mathrm{YTa}_{7} \mathrm{O}_{19}$ (Fig. 5) with plateaus, suggesting the possibility of different conduction mechanisms with increasing voltage.

\section{SUMMARY}

The structural and physical properties of as-deposited and annealed Eu- and Y-polytantalate thin films on Si wafers and have been studied using various techniques. These films show very similar behavior, both as-deposited and after annealing, revealing their similarity in morphology, indexes of refraction, band gaps and dielectric properties. The as-deposited amorphous films have a smooth interfacial $\mathrm{SiO}_{2}$ layer when deposited on $\mathrm{Si}$. Annealing the films results in a thicker $\mathrm{SiO}_{2}$ interfacial layer. Annealed films have an anisotropic crystalline structure and exhibit a degradation of most of the useful dielectric properties compared to the amorphous films (lower K-value, higher leakage current, lower density and breakdown field). Further work is needed to optimize annealing parameters and to determine the conduction mechanisms in these films. Nevertheless, the results indicate that these rare-earth polytantalates, both amorphous and crystalline, are promising candidates for high-K dielectrics.

\section{REFERENCES}

1. V. Vasilyev, A. Drehman, and L. Bouthillette, MRS Symp. Proc., 749 (2003) W5.8.1.

2. P. Young, J. Appl. Phys. 47 (1), 235 - 247 (1976).

3. C. Chaneliere, J.L. Autran, R.A.B. Devine, B. Balland, Mater. Sci. Eng., R22, 269-322 (1998).

4. K. Onisawa, M. Fuyama, K. Tamura, K. Taguchi, T. Nakayama, and Y.A. Ono, J. Appl. Phys., 68 (2), 719-723 (1990).

5. A. Paskaeva, E. Atanassova, and T. Dimitrova, Vacuum, 58, 470 - 477 (2000).

6. E.K. Lin, W.W. Wu, C. Jin, J.F. Wetzel, MRS Proc. 612 (2000) D4.1.1.

7. S. Kohli, D. Niles, C.D. Ritner, P.K. Dorhout, Advances in X-Ray Analysis, 45, 352 (2002).

8. M. Wormington, C. Panaccione, K.M. Matney, D.K. Bowen, Phil. Trans. R. Soc. Lond. A357, 2827-2848 (1999).

9. H. G. Tompkins and W. A. McGahan, "Spectroscopic Ellipsometry and Reflectometry: A User's Guide", J. Wiley \& Sons, NY (1999).

10. V. Vasilyev and M.M. Pinaeva, Rus. J. Inorg. Chem., 25 (4), 500-504 (1980).

11. B.M. Gatehouse, J. Solid State Chem., 27, 209 (1979).

12. B. Langenbach-Kuttert, J. Sturm, R. Gruehn, Z. Anorg Allg Chem., 543, 117-128 (1986).

13. U. Shaffrath and R. Gruehn, Z. Anorg. Allg. Chem., 588, $43-54$ (1990).

14. G.-C. Guo, J.-N. Zhuang, Y.-G. Wang, J.-T. Chen, H.-H. Zhuang, J.-S. Huamg and Q.-E. Zhang, Acta Cryst., C52, 5-7 (1996).

15. E. Cavalli, L.I. Leonyuk, and N.I. Leonyuk., J. of Crystal Growth, 224, 67-73 (2001).

16. V. Vasilyev, M. Pinaeva, and G. Pinaev, Doklady Physics, 48 (1), 21-23 (2003).

17. J. Tauc. In “Optical Properties of Solids", Ed. By F. Abeles, North Holland (1969).

* Supported by the Air Force Office of Scientific Research, through the NRC Associateship Program. 